\title{
Imagens da técnica no romance 1984, de George Orwell
}

\section{Images of the technique in George Orwell's novel 1984}

\section{João Batista Santiago SOBRINHO* CEFET-MG}

\section{Leonardo David de MORAIS** CEFET-MG}

Resumo: O objetivo deste artigo é propor uma análise do romance 1984, do escritor britânico George Orwell, a partir dos conceitos de "dispositivo" e "técnica”, interpretados, respectivamente, pelos pensadores italianos Giorgio Agamben e Umberto Galimberti. Na narrativa de Orwell, as imagens, notadamente aquelas veiculadas através de aparatos como a "teletela”, exercem não apenas a função de divertir ou informar, mas também de direcionar as ações das personagens ao longo do enredo. Nesse sentido, buscou-se articular os conceitos mencionados a um elemento que se destaca na trama orwelliana: a "imagem técnica”, no sentido cunhado por Vilém Flusser.

Palavras-chave: 1984. Dispositivo. Imagem. Técnica. Distopia.

\begin{abstract}
The objective of this paper is to propose an analysis of George Orwell's novel 1984 from the concepts of "device" and "technical”, interpreted respectively by Umberto Galimberti and Giorgio Agamben. In the Orwell's narrative, images, notably those related through certain devices like the "telescreen", performing the function of not only entertain or inform, but to direct the actions of the characters throughout the storyline. Accordingly, we sought to articulate the concepts referred to an element that stands out in orwellians plot: the "technical image" in the sense coined by Vilém Flusser.
\end{abstract}

Keywords: 1984 . Device. Image. Technique. Dystopia.

\author{
* Professor doutor \\ do Centro Federal de \\ Educação Tecnológica \\ do Estado de Minas \\ Gerais - CEFET-MG; \\ joaoliter@hotmail.com \\ ${ }^{* *}$ Mestrando em \\ Estudos de Linguagens \\ pelo CEFET-MG; \\ leodemorais@gmail. \\ com
}




\section{A imagem técnica}

Quem se poderá esconder da (luz) que nunca se deita. Heráclito de Éfeso

No romance 1984, a "técnica", entendida aqui a partir do conceito de Umberto Galimberti, presente em Psiche e techne: o homem na idade da técnica, ${ }^{1}$ como uma forma de pensar, uma maneira de agir sobre o mundo que privilegiaria o meio, o instrumento, nos parece ser plasmada através de diversos tipos de "imagens"; estas que, segundo o estudioso do tema, Vilém Flusser, "são superfícies que pretendem representar algo. Na maioria dos casos, algo que se encontra lá fora no espaço e no tempo" (FLUSSER, 1985, p. 7). Flusser, inclusive, foi mais longe em suas análises e definições sobre o conceito de "imagem", delimitando uma espécie em particular que nos interessa sobremaneira neste texto, a qual ele definiu como "imagem técnica”, uma imagem programada, calculada, isto é, a "imagem produzida por aparelhos” (FLUSSER, 1985, p. 10).

Analogamente a essa "imagem técnica", desprovida de qualquer afetividade, de que nos fala Flusser, "imagens programadas" se manifestam por intermédio dos mais diversos suportes e aparatos ao longo das páginas do romance 1984 - que, publicado em 1949, emoldura alguns aspectos perversos dos governos de sua época. Naturalmente que tais manifestações, no enredo orwelliano, não visam a oferecer apenas entretenimento e informação cotidiana a seus personagens-espectadores. Ao contrário, a imagem técnica da "distopia” orwelliana - isto é, de uma "utopia” que não deu certo, que fracassou no seu intuito idealista de um mundo melhor, habitado por pessoas melhores (COELHO, 1985) -, contém, confeccionada pelo Estado totalitário, peça fundamental no enredo do romancista britânico, uma vontade de controle implacável e levada a cabo por meio de uma onipresente vigilância estendida a todos: "O GRANDE IRMÃO ESTÁ DE OLHO EM VOCÊ”. (ORWELL, 2009, p. 12, grifo do autor), digamos, a “GRANDE IMAGEM”, que se quer única no imaginário de todos.

O romance de Orwell guarda semelhanças importantes com outros livros de crítica aos Estados totalitários, como, por exemplo, Nós (2004), escrito entre 1920 e 1921, de Evgueny Zamiatin. Em Nós, o Grande Irmão é chamado de Benfeitor. Trata-se de uma crítica vigorosa à recém-criada União Soviética e valeu ao autor uma terrível perseguição, até que, em 1931, com ajuda de Máximo Gorki, foi obrigado a exilar-se em Paris, onde viveu até morrer em 1937. Logo no início do romance Nós, temos a seguinte passagem que vale a pena destacar: "Em nome do Benfeitor anunciamos a todos os números do Estado Unificado: Cada um, que se sentir com forças, é obrigado a compor tratados, poemas, manifestos e odes ou outras composições sobre a beleza e grandeza do Estado Unificado" (ZAMIATIN, 2004, p. 9). Esse livro inspirará, ainda, Admirável mundo novo, de Aldoux

\footnotetext{
${ }^{1}$ Segundo Galimberti, "com o termo técnica entendemos tanto o universo dos meios (as tecnologias), que em seu conjunto compõem o aparato técnico, quanto a racionalidade que preside o seu emprego, em termos de funcionalidade e eficiência. Com essas características, a técnica nasceu, não como expressão do 'espírito’ humano, mas como 'remédio' à sua insuficiência biológica” (GALIMBERTI, 2006, p.9).
} 
Huxley, escrito em 1932. Gregory Claeys, no livro Utopia: a história de uma ideia, no capítulo "Totalitarismo e pós-totalitarismo na sátira e na realidade", afirma que "o novo subgênero de distopia comunista aparece de modo seminal com a publicação de Nós (1924) [...], a mais importante sátira sobre o bolchevismo e um poderoso ataque à centralização estatal e à supressão de individualidade” (CLAEYS, 2013, p. 177). Tanto a centralização estatal quanto a supressão de individualidade são aspectos recorrentes em 1984.

Importante acrescentar que a imagem técnica, e mesmo os aparatos nos quais esse discurso totalitário se manifesta ao longo da narrativa orwelliana, aproxima-se em muitos aspectos do conceito de "dispositivo" do pensador italiano Giorgio Agamben, que o elabora tomando emprestado uma plêiade de estudos que se inicia com Michel Foucault (dispositivo), mas dialoga também com Martin Heidegger (armação), Ernst Jünger (mobilização total) e Herbert Marcuse (Homem unidimensional), por exemplo. Todos esses autores revelam uma preocupação com os destinos do processo civilizatório capitaneado hegemonicamente pela técnica. Nesse sentido, é esclarecedora a definição de Agamben:

[...] chamarei literalmente de dispositivo qualquer coisa que tenha de algum modo a capacidade de capturar, orientar, determinar, interceptar, modelar, controlar e assegurar os gestos, as condutas, as opiniões e os discursos dos seres viventes. Não somente, portanto, as prisões, os manicômios, o Panóptico, as escolas, a confissão, as fábricas, as disciplinas, as medidas jurídicas etc., cuja conexão com o poder é num certo sentido evidente, mas também a caneta, a escritura, a literatura, a filosofia, a agricultura, o cigarro, a navegação, os computadores, os telefones celulares - e por que não - a própria linguagem. (AGAMBEN, 2012, p. 40-41)

Dessa forma, um dos aparatos tecnológicos que consideramos ser elemento-chave do estudo da narrativa de Orwell aqui proposto, a "teletela”, revela-se perfeitamente dentro da aura ramificante do dispositivo alinhavado por Agamben. O dispositivo é uma forma, uma maneira de assegurar o controle sobre toda forma de vida e se dilui por todas as filigranas do imaginário social como uma "máquina de criar subjetividades”. Com esse conceito, procuraremos, ao modo flusseriano, "des-ocultar os programas por trás das imagens” (FLUSSER, 2008, p. 29). Caso não se consiga des-ocultar esses programas, corre-se o risco de que as imagens se transformem, opacas, em nova forma de idolatria, semelhante às imagens tradicionais, antes da invenção da escrita, dirá Flusser. De muitas maneiras, a opacidade das imagens programadas, em 1984, converterá o “Grande Irmão" na causa inicial e final de todos os personagens desse romance, no qual o protagonista representa, de muitas maneiras, o último reduto a ser alcançado pela lógica do controle que o cerca. 
Antes de avançarmos rumo às idiossincrasias da técnica que mencionamos acerca da narrativa de Orwell, convém mais uma vez evocarmos Galimberti e o conceito de "técnica” que esse filósofo elabora, uma vez que a "teletela” pode ser considerada como “dispositivo”, capaz de proporcionar a materialização e a manutenção de uma subjetividade única, por intermédio de uma rede de procedimentos que traduz uma só vontade, muito semelhante à idade da técnica, conforme a vê Galimberti. Para esse filósofo italiano, "o fundamento da vontade é a técnica, sem a qual não se dá o ato voluntário, mas uma simples ação causal, com cujo resultado não se pode contar e, sobretudo, dele não se pode dispor à vontade” (GALIMBERTI, p. 282). Dessa forma, toda a ação decorre de seu fundamento, a técnica, que coloca o mundo em disponibilidade. Galimberti certamente dialoga com Heidegger na citação acima, particularmente com o texto “A questão da técnica” (HEIDEGGER, 2008), no qual o autor explora esse fator totalitário da técnica de se apropriar da vida e colocála à disposição para o uso exploratório do capital. A técnica "dis-põe do mundo no sentido de uma exploração” (HEIDEGGER, 2008, p. 19), com o máximo de rendimento e o mínimo de gasto.

No romance de Orwell, uma das maneiras encontradas pelas forças distópicas para vigiar e controlar os habitantes da metrópole em que o personagem Winston vive sua tragédia foi a criação da “teletela”, um aparato eletroeletrônico semelhante ao aparelho de televisão, que transmite ininterruptamente apenas a programação produzida pelo Estado ditatorial ficcionalizado no romance. Todos são obrigados a ficar diante da teletela em certos momentos do dia, como a prestar contas ao Estado:

No interior do apartamento, uma voz agradável lia alto uma relação de cifras que de alguma forma dizia respeito à produção de ferro-gusa. A voz saía de uma placa oblonga de metal semelhante a um espelho fosco, integrada à superfície da parede da direita. Winston girou um interruptor e a voz diminuiu um pouco, embora as palavras continuassem inteligíveis. $\mathrm{O}$ volume do instrumento (chamava-se teletela) podia ser regulado, mas não havia como desligá-lo completamente. (ORWELL, 2009, p. 12)

A onipresença invasiva dessa forma de controle arquitetada por um recurso midiático poderoso assemelha-se, em muitos aspectos, aos gadgets, as “aberrações funcionais” que, segundo Jean Baudrillard, regem nossa vida hoje. Baudrillard parece descrever um mundo ficcional quando se refere ao poder dos gadgets geradores do automatismo. Para o sociólogo francês,

o automatismo é somente um desvio técnico, mas abre para o universo inteiro do delírio funcional. Dito de outra forma, todo o campo dos objetos fabricados em que atua a complicação irracional, a obsessão pelo detalhe, o tecnicismo excêntrico e o formalismo gratuito. Nessa zona poli-para-hiper 
e meta-funcional, o objeto, longe das determinações objetivas, é desta vez tomado inteiramente pelo imaginário. No automatismo projetava-se irracionalmente a imagem da consciência, neste mundo "esquizofuncional" inscrevem-se unicamente as obsessões puras e simples. Trata-se de toda uma patafísica do objeto que seria preciso aqui escrever ou ciência das soluções técnicas imaginárias. (BAUDRILLARD, 2008, p. 121)

Interessa-nos na citação acima destacar o caráter viral do automatismo que leva o “usuário”, cujo imaginário foi cooptado para o sistema disposto pela técnica, à dimensão mais importante desta, aquela que Galimberti também ressalta quando diz, por seu turno, que ela simplesmente funciona: “[a técnica] de fato, não tende a um objetivo, não promove um sentido, não abre cenários de salvação, não redime, não desvenda a verdade: a técnica funciona" (GALIMBERTI, 2006, p. 8). É por esse aspecto que também nos tornamos funcionários autômatos da técnica. Ironicamente, Baudrillard afirma que esse automatismo criado pelos gadgets cria uma espécie de delírio funcional, naturalmente adequando o usuário a uma lógica perversa - no romance que estamos analisando, à lógica do Estado; e, na contemporaneidade, à lógica do mercado.

Na literatura de Orwell, escrita em 1948, como na vida atual, a realidade é construída diuturnamente e mantida por meio de aparatos que, pela natureza de sua utilização, transformam-se em “dispositivos” para exercer, por meio da técnica, o controle total e irrestrito sobre a vida de seus cidadãos. No caso particular da teletela, vemos, ainda, um outro detalhe que nos parece importante acerca desse aparato-dispositivo: a capacidade de captar todos os sons e imagens emitidos por seu espectador durante o tempo em que permanecesse em sua residência:

Por trás de Winston, a voz da teletela continuava sua lenga-lenga infinita sobre o ferro-gusa e o total cumprimento - com folga - das metas do Nono Plano Trienal. A teletela recebia e transmitia simultaneamente. Todo som produzido por Winston que ultrapassasse o nível de um sussurro muito discreto seria captado por ela; mais: enquanto Winston permanecesse no campo de visão enquadrado pela placa de metal, além de ouvido também poderia ser visto. Claro, não havia como saber se você estava sendo observado num momento específico. [...] Era possível que ela controlasse todo mundo o tempo todo. [...] Você era obrigado a viver - e vivia, em decorrência do hábito transformado em instinto - acreditando que todo som que fizesse seria ouvido e, se a escuridão não fosse completa, todo movimento examinado meticulosamente. (ORWELL, 2009, p.13)

\section{A distopia funcional}

Conforme entrevisto, acreditamos que os conceitos de "utopia” e de “distopia”, enquanto maneiras de conceber um mundo ideal - mundo 
que, em dado momento, torna-se uma espécie de versão perversa, cópia deformada de si mesmo - foram largamente utilizados por George Orwell para construir, na narrativa, o tempo-espaço do romance. O discurso de O’Brien, antagonista e carrasco do protagonista Winston, ilustra nossa hipótese sobre o processo da criação de uma “distopia”, na trama, em oposição às “utopias” tradicionais:

Está começando a ver que tipo de mundo estamos criando? Exatamente o oposto das tolas utopias hedonistas imaginadas pelos velhos reformadores. Um mundo de medo e traição e tormento, um mundo em que um pisoteia o outro, um mundo que se torna mais e não menos cruel à medida que evolui. O progresso, no nosso mundo, será o progresso da dor. As velhas civilizações diziam basear-se no amor ou na justiça. A nossa se baseia no ódio. No nosso mundo, as únicas emoções serão o medo, a ira, o triunfo e a autocomiseração. Tudo o mais será destruído - tudo. (ORWELL, 2009, p. 311-312)

Sobre a ideia de “utopia”, entendida como uma espécie de ponto de ruptura, geradora de tensões e transformações que ocorreram em determinados contextos sócio-históricos, Teixeira Coelho afirma:

Até fins do século XVIII, as utopias eram vistas ou como discussões filosóficas (no caso da República) ou como gênero literário [...]. A partir da Revolução Francesa, porém, os projetos de reforma social surgem cada vez mais sob a luz da possibilidade de sua realização efetiva, desde que indivíduos, grupos e classes estivessem dispostos a tentá-la. Nesse momento, a utopia deixa de ser um caso de literatura e transforma-se em questão, hipótese e caminho da política. (COELHO, 1980, p. 50)

Na história concebida por Orwell, a sociedade da qual o narrador-personagem Winston faz parte foi reconstruída após uma grande guerra, quando o capitalismo aparentemente deixou de existir, sendo substituído por uma estrutura de poder que visa unicamente a manter-se enquanto tal. Para tanto, destrói qualquer ameaça por intermédio de uma rede perversa de ações subliminares - quando não violentamente explícitas - que mantêm os cidadãos em estado de alerta. Todos, nessa sociedade orwelliana são potencialmente inimigos de todos.

Em 1984, não ocorre a edificação de um corpo social hierarquizado, em um locus ideal, conforme pensara Platão em sua República (PLATÃO, 2001), mas sim a materialização de uma sociedade, sob ubíqua vigilância e doutrinação sistemática do Estado, que submete seus cidadãos a um contínuo apagamento das individualidades, em favor de uma coletividade subserviente. Neste ponto, evocamos mais um trecho da fala do personagem O’Brien, uma espécie de porta-voz do discurso oficial imposto pela derrocada da diferença, pela perda da identidade, em nome da coletividade massificada, imaginada pelo romancista Orwell: 
A primeira coisa que precisa entender é que o poder é coletivo. O indivíduo só consegue ter poder na medida em que deixa de ser um indivíduo. [...] Sozinho - livre - o ser humano será sempre derrotado. [...] Mas se ele atingir a submissão total e completa, se conseguir abandonar sua própria identidade, se conseguir fundir-se com o Partido a ponto de ser o Partido, então será todo-poderoso e imortal. (ORWELL, 2009, p. 309, grifo do autor)

Ainda a propósito da distopia, materializada não apenas no contexto específico de uma narrativa literária, mas plasmada em nosso imaginário cultural contemporâneo, Rogério Bianchi de Araújo, no texto "A revolução tecnocientífica e a distopia no imaginário ocidental” (2011), atribui ao termo uma ação cuja consequência resultaria no cerceamento da liberdade:

[...] o movimento da utopia para a distopia é marca da sociedade contemporânea. Enquanto as utopias buscam a emancipação ao visualizar um mundo baseado em ideias novas que têm por características em comum serem negligenciadas ou rejeitadas, as distopias procuram demonstrar tendências contemporâneas que podam a liberdade humana. (ARAÚJO, 2011, p. 5)

Ora, para que servem a "teletela” e outros “dispositivos” geradores de "imagens técnicas”, na trama de 1984, a não ser justamente para doutrinar e controlar eficientemente os corações e mentes de seus personagens?

Conforme mencionado, a imagem técnica não se materializa em 1984 apenas sob a forma de programação estatal televisiva veiculada nas teletelas. As imagens impressas, sobretudo as dos pôsteres e cartazes espalhados pela Londres do romance de Orwell, nos parecem também exercer a função de dispositivo - ainda no sentido cunhado por Agamben - uma vez que, através do seu conteúdo ideológico, impõem aos seus cidadãos, como verdade única e inquestionável, o discurso concebido e emanado por um Estado totalitário. Considerando, então, que dispositivo pode ser qualquer coisa que ajude a exercer algum tipo de controle sobre um indivíduo, a imagem ameaçadora de um soldado inimigo impressa em um grande cartaz parece confirmar nossa hipótese de que as imagens técnicas, adotadas por esse Estado totalitário, em 1984, cumpre perfeitamente o papel de dispositivo, já que a visão ampliada de um inimigo inspira medo, exercendo, portanto, alguma forma de controle:

De repente, aparecera por toda Londres um novo cartaz. Não tinha legenda, e representava simplesmente a monstruosa figura de um soldado eurasiano, de três ou quatro metros de altura, avançando com enormes botas e uma cara mongólica sem expressão, apontando uma metralhadora portátil apoiada no quadril. De onde quer que se olhasse o cartaz, o cano da metralhadora, ampliado pela perspectiva, parecia apontar para a gente. (ORWELL, 2009, p. 108) 
Trata-se de um “novo cartaz” para a representação do mesmo, em eterno retorno, para difundir, conforme se vê, massivamente, a "imagem técnica” do “Grande Irmão":

Numa das extremidades, um pôster colorido, grande demais para ambientes fechados, estava pregado na parede. Mostrava simplesmente um rosto enorme, com mais de um metro de largura: o rosto de um homem de uns quarenta e cinco anos, de bigodão preto e feições rudemente agradáveis. (ORWELL, 2009, p. 11)

Importante ressaltar o caráter de onipresença - uma das características da técnica, segundo Galimberti - que as imagens técnicas, impressas em cartazes e pôsteres, parecem impor ao personagem: "Em todos os patamares, diante da porta do elevador, o pôster com o rosto enorme fitava-o da parede. Era uma dessas pinturas realizadas de modo a que os olhos o acompanham sempre que você se move” (ORWELL, 2009, p. 12).

Ainda sobre o caráter de onisciência e onipresença atribuído à técnica, característica que se relaciona às sociedades submetidas às mais diversas formas de controle, que, por sua vez, é levado a termo através de uma série de dispositivos, nos parece importante evocar mais uma vez o pensamento de Agamben, para constatarmos algo que, já mencionado em relação à teletela, é um dos pontos fulcrais não apenas da trama de 1984, mas de grande parte das sociedades contemporâneas: a vigilância:

É por um paradoxo apenas aparente que o inócuo cidadão das democracias pós-industriais, que executa pontualmente tudo o que lhe é dito e deixa que os seus gestos quotidianos, como sua saúde, os seus divertimentos, como suas ocupações, a sua alimentação, como o seu desejo sejam comandados por dispositivos até nos mínimos detalhes, é considerado pelo poder - talvez por isso mesmo - como um terrorista virtual [...] a vigilância por meio de videocâmara transforma os espaços públicos das cidades em áreas internas de uma imensa prisão. Aos olhos da autoridade - e, talvez, esta tenha razão - nada se assemelha melhor ao terrorista do que homem comum. (AGAMBEN, 2012, p. 40-41)

Nesse sentido, cabe aqui salientar a atualidade do romance de Orwell acerca do tema, uma vez que o autor, a partir de uma narrativa concebida ainda na década de 40 do século passado, ambientada em um futuro distópico localizado cerca de quatro décadas adiante, ainda oferece um espaço para ampla reflexão, no contexto do imaginário cultural contemporâneo, das relações decorrentes entre os “dispositivos" e os "seres” que, segundo outro compatriota de Agamben, Galimberti, estão sujeitos, fatalmente, a um agir e pensar regidos estritamente pela técnica.

Na sociedade representada no romance 1984, o controle do Estado sobre seus cidadãos era exercido em todas as instâncias de suas vidas, 
sobretudo no âmbito do consumo “intelectual” e "sexual”. Nesse sentido, imagens técnicas também foram usadas para ampliar o nível de controle sobre todos os personagens da trama:

E, no fim das contas, o Departamento de Documentação não passava de um ramo do Ministério da Verdade cuja função primeira não era reconstruir o passado e sim abastecer os cidadãos da Oceânia com jornais, filmes, livros escolares, programas de televisão, peças dramáticas [...] Ali eram produzidos jornais populares contendo apenas e tão somente esportes, crimes e astrologia, romances sem a menor qualidade [...] filmes com cenas e mais cenas de sexo [...]. Havia inclusive uma subseção inteira - Pornodiv era seu nome em Novafala - dedicada à produção do tipo mais grosseiro de pornografia, que era despachado em embalagens fechadas e que nenhum integrante do Partido, salvo os envolvidos em sua produção, tinha a permissão de ver. (ORWELL, 2009, p. 57-58, grifo do autor)

Ao monopolizar a produção de imagens técnicas de cunho sexual, fica mais evidente a intenção do Estado totalitário, regido pelo "Grande Irmão”, de avançar e impor absoluto controle acerca de cada um dos aspectos da vida de seus cidadãos, até mesmo aqueles de cunho mais íntimo. Ainda nesse sentido, a trama oferece mais alguns exemplos sobre tal modus operandi de controle total sobre as manifestações relativas à sexualidade, e, consequentemente, da reprodução das personagens no enredo:

O único propósito reconhecido do casamento era gerar filhos para servir ao Partido. A relação sexual deveria ser encarada como uma operaçãozinha ligeiramente repulsiva, uma espécie de lavagem intestinal. [...] Havia inclusive organizações que defendiam o celibato absoluto para ambos os sexos. Todas as crianças seriam geradas por inseminação artificial e criadas em instituições públicas [...]. O Partido tratava de aniquilar o impulso sexual e, não podendo aniquilá-lo, queria pelo menos distorcê-lo e aviltá-lo. (ORWELL, 2009, p. 84)

Ao longo da história da humanidade, a concepção e imposição de determinadas ideologias, ainda que concebidas com a melhor das intenções, como geralmente são criadas também as “utopias”, converteram-se facilmente, por meio da técnica, em ferramentas de repressão e controle. Em consequência desse movimento, a "utopia” desejada, o processo civilizatório, se transforma em barbárie, ou seja, em “distopia”.

\section{Conclusão}

Conforme analisado, as manifestações da "imagem técnica" exerceram sobre os personagens da sociedade, em 1984, imaginada pelo escritor George Orwell, a função de “dispositivo”, no sentido de controle, como proposto por Giorgio Agamben. Algumas das imagens técnicas, 
materializadas ao longo da narrativa orwelliana através de uma série de dispositivos (a teletela, pôsteres e cartazes, material pornográfico), não operavam apenas no sentido de entreter ou de informar seus espectadorespersonagens. Tinham por objetivo, programaticamente, levar a cabo o controle total desses indivíduos, por meio da propagação de da ideologia do pensamento único que, ao longo da trama, é intensificado, até que não sobre nenhuma diferença. Cabe aqui tomarmos emprestado, novamente de Vilém Flusser - como uma advertência! -, um dos conceitos sobre o tipo de “imagem” e de sua função como “dispositivo", relativa ao controle do indivíduo e que se aplica perfeitamente não apenas à trama do britânico Orwell, mas também, perigosamente, ao nosso atual contexto sóciohistórico, dentro do qual somos provocados a pensar e agir nos moldes da técnica: “[...] as imagens técnicas significam programas. São projeções que partem de programas e visam programar os seus receptores. As cenas mostradas pelas imagens técnicas são métodos de como programar $a$ sociedade” (FLUSSER, 2008, p.72-73, grifos nossos).

\section{Referências}

AGAMBEN, Giorgio. O que é o contemporâneo? e outros ensaios. Tradução de Vinícius Nicastro Honesco. Chapecó, SC: Argos, 2013.

ARAÚJO, Rogério Bianchi. A revolução tecnocientífica e a distopia no imaginário ocidental. Revista Brasileira de Ciência, Tecnologia e Sociedade, São Carlos: v.2, n.1, p.2-11, jan./jul. 2011.

BAUDRILLARD, Jean. O sistema dos objetos. Tradução de Zulmira Ribeiro Tavares. São Paulo: Perspectiva, 2008.

CLAEYS, Gregory. Utopia: a história de uma ideia. Tradução de Pedro Barros. São Paulo: Sesc, 2013.

COELHO, Teixeira. O que é utopia. São Paulo: Abril Cultural-Brasiliense, 1985.

FLUSSER, Vilém. Filosofia da caixa preta: ensaios para uma futura filosofia da fotografia. São Paulo: Editora Hucitec, 1985.

FLUSSER, Vilém. O universo das imagens técnicas: elogio da superficialidade. São Paulo: Annablume, 2008.

GALIMBERTI, Umberto. Psiche e techne: o homem na idade da técnica. Tradução de José Maria de Almeida. São Paulo: Paulus, 2006.

HEIDEGGER, Martin. Ensaios e conferências. Tradução de Emmanuel Carneiro Leão, Gilvan Fogel, Marcia Sá Cavalcante Schuback. Petrópolis: Vozes, 2008. 
ORWELL, George. 1984. Tradução de Heloisa Jahn e Alexandre Hubner. São Paulo: Companhia das Letras, 2009.

PLATÃO. A República. Lisboa: Fundação Calouste Gulbenkian, 2001.

ZAMIATIN, Evgueny. Nós. Tradução de Clarice Lima Averina. São Paulo: Editora Alfa-Omega, 2004.

Enviado: 01/10/2014

Aprovado: 15/11/2014 